\title{
Changes in the Metabolic Clearance of Vasopressin and in Plasma Vasopressinase throughout Human Pregnancy
}

\author{
John M. Davison, Elizabeth A. Sheills, William M. Barron, ${ }^{\ddagger}$ Alan G. Robinson, ${ }^{\star}$ and Marshall D. Lindheimer ${ }^{\star}$
}

Medical Research Council (MRC) Human Reproduction Group, Princess Mary Maternity Hospital, University of Newcastle, Newcastle upon Tyne, NE2 3BD United Kingdom; *Departments of Medicine, University of Pittsburgh Medical School, Pittsburgh, Pennsylvania 15261; and $\ddagger^{\ddagger}$ Departments of Obstetrics and Gynecology and Medicine, University of Chicago, Chicago, Illinois 60637

\section{Abstract}

Metabolic clearance rates (MCR) of arginine vasopressin (AVP) were measured serially in five women starting before conception, during gestational weeks 7-8 (early), 22-24 (middle), and 36-38 (late pregnancy), and again 10-12 wk postpartum. Hormonal disposal rates were determined after water loading to suppress endogenous AVP release using a constant infusion method designed to achieve three different steadystate concentrations of plasma AVP $\left(P_{A V P}\right)$ on each test occasion. Dose schedules were altered in mid- and late pregnancy to obtain comparable AVP levels at each stage of the protocol. Prehydration decreased plasma osmolality sufficiently to suppress AVP release, as circulating AVP-neurophysin measured serially in three of the women was undetectable. The MCR of AVP was similar before conception $(0.75 \pm 0.31,0.79 \pm 0.34$, and $0.76 \pm 0.28 \mathrm{liters} / \mathrm{min}$ at $P_{\mathrm{AVP}}$ of $2.6 \pm 1.9,4.7 \pm 2.4$, and $8.3 \pm 3.9 \mathrm{pg} / \mathrm{ml})$, in early pregnancy $(0.89 \pm 0.34,0.97 \pm 0.04$, and $0.95 \pm 0.40$ liters $/ \mathrm{min}$ at $P_{A V P}$ of $2.2 \pm 2.1,3.9 \pm 3.2$, and $7.9 \pm 3.4 \mathrm{pg} / \mathrm{ml})$, and postpartum $(0.70 \pm 0.21,0.69 \pm 0.24$, and $0.75 \pm 0.20$ liters/min at $P_{\text {AvP }} 3.5 \pm 1.8,5.1 \pm 3.7$, and 9.1 \pm 4.2 $\mathrm{pg} / \mathrm{ml})$. Values at mid-pregnancy $(2.8 \pm 1.3,3.0 \pm 1.2$, and 2.7 \pm 1.2 liters $/ \mathrm{min}$ at $P_{\mathrm{AVP}} 2.3 \pm 2.2,4.0 \pm 3.6$, and $7.7 \pm 3.9$ $\mathrm{pg} / \mathrm{ml})$ and late pregnancy $(3.2 \pm 1.4,3.3 \pm 1.4$, and $2.9 \pm 1.2$ liters $/ \mathrm{min}$ at $P_{A v P} 1.9 \pm 2.0,3.8 \pm 2.6$, and $7.4 \pm 4.1 \mathrm{pg} / \mathrm{ml}$ ) increased 3-4-fold (all $P<0.01$ ). Plasma vasopressinase, undetectable at 7-8 gestational wk, increased markedly by mid- and slightly more by late gestation. Finally, relationships between $\mathbf{P}_{\mathrm{AvP}}$ and urine osmolality were similar before, during, and after pregnancy. We conclude that marked increments in the MCR of AVP occur between gestational weeks 7 and 8 and mid-pregnancy, which parallel the period of greatest rise in both trophoblastic mass and plasma vasopressinase. There was no evidence of a renal resistance to AVP during gestation.

\section{Introduction}

Human gestation is characterized by profound alterations in osmoregulation. Plasma osmolality $\left(\mathrm{P}_{\text {osmol }}\right)^{1}$ and osmotic

Reprint requests from Great Britain and the Eastern hemisphere should be addressed to Dr. Davison, MRC Reproduction Group, Princess Mary Maternity Hospital, University of Newcastle, Newcastle upon Tyne, NE2 3BD, UK. Reprint requests from the Western hemisphere should be addressed to Dr. Lindheimer, Department of Medicine, Section of Nephrology, Box 453, 5841 South Maryland Avenue, Chicago, IL 60637.

Received for publication 22 August 1988 and in revised form 18 November 1988.

1. Abbreviations used in this paper: DDAVP, 1-desamino-[8-D-arginine] vasopressin; DI, diabetes insipidus; MCR, metabolic clearance

J. Clin. Invest.

(c) The American Society for Clinical Investigation, Inc.

0021-9738/89/04/1313/06 \$2.00

Volume 83, April 1989, 1313-1318 thresholds for thirst and arginine vasopressin (AVP) release decrease $\sim 10 \mathrm{mosmol} / \mathrm{kg}$ during the first trimester. These decrements are maintained till term (1-3). Another interesting osmoregulatory change is that the rise in circulating AVP levels provoked by increases in body tonicity $\left(\Delta \mathrm{P}_{\mathrm{AVP}} / \Delta \mathrm{P}_{\text {osmol }}\right)$, unaltered early in gestation, is markedly decreased in the third trimester (3). This latter event could represent a reduced secretory response to osmotic stimuli, but might also reflect an increase in hormonal metabolic clearance rates (MCR). Indeed, in a preliminary report we have noted that the MCR are increased fourfold during the third trimester compared with measurements postpartum (4). The present study extends this latter observation. MCR of AVP were measured serially in volunteers, starting before conception, continuing throughout pregnancy, and again 10-12 wk postpartum. This study was designed to determine hormonal disposal rates at three different steady-state plasma concentrations during each test. Furthermore, by manipulating exogenous AVP infusion rates we succeeded in duplicating these levels and were able to compare their influence both on the MCR and urine osmolality ( $\left.U_{\text {osmol }}\right)$ first before, three times during, and again after pregnancy. Results were also correlated with circulating levels of cystineaminopeptidase (EC 3.4.11.3; vasopressinase), an enzyme recently implicated in the etiology of transient vasopressin-resistant diabetes insipidus (DI) of pregnancy (5).

\section{Methods}

\section{Subjects}

Serial studies were performed on five normotensive healthy subjects once before conception, between gestational weeks 7 and 8,22 and 24, 36 and 38 (designated as early, mid-, and late pregnancy), and again 10-12 wk postpartum, when none were breast feeding or ingesting oral contraceptives. In addition, two women with a single kidney, one subject carrying twins and another triplets, were studied but only in late pregnancy and postpartum. All volunteers gave informed consent in writing to protocols approved by both the Ethical Committee of Newcastle Health Authority and the Clinical Investigation Committee of the University of Chicago Pritzker School of Medicine. All subjects had successful pregnancies.

\section{Protocols}

Fig. 1 is a schema of the protocol. Each study began at 9:00 a.m. with the volunteers seated comfortably. Control blood samples were obtained and an infusion of normal saline $(0.03 \mathrm{ml} / \mathrm{kg}$ per $\mathrm{min})$ was started, after which the subject drank $20 \mathrm{ml} / \mathrm{kg}$ of tap water. Clearance measurements began $1 \mathrm{~h}$ later and after $\mathrm{U}_{\text {osmol }}$ had decreased below 100 mosmol/kg. Three AVP (Argipressin; Parke-Davis, Detroit, MI) delivery rates, each preceded by a priming dose, were used during each test (Fig. 1). ${ }^{2}$ Each infusion was maintained for $75 \mathrm{~min}$, urine collected at

rates; $\mathbf{P}_{\mathrm{AVP}}$, plasma arginine vasopressin; $\mathrm{P}_{\mathrm{osmol}}$, plasma osmolality; $\mathrm{U}_{\text {osmol }}$, urine osmolality.

2. Dose schedules, altered in mid- and late pregnancy to obtain comparable levels at each stage of the protocol, were based on preliminary 


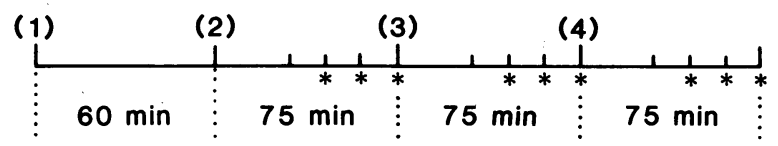

(1) Ingest water load $(20 \mathrm{ml} / \mathrm{kg})$ and begin sustaining infusion. After 60 min., priming dose followed by constant AVP infusion (*denotes blood sampling) PRIME DELIVERY $(\mathrm{pg} / \mathrm{kg}) \quad(\mathrm{pg} / \mathrm{kg} / \mathrm{min})$

(2) nonpregnant; early pregnancy midoestation; late pregnancy

35

120

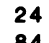

(3) non pregnant: early pregnancy midgestation: late pregnancy

\section{0}

210

42

(4) nonpregnant: early pregnancy midgestation: late pregnancy 105 360 24 144 72

Figure 1. Schema of infusion protocol.

15-min intervals during the last $45 \mathrm{~min}$, and blood samples obtained at 45,60 , and $75 \mathrm{~min}$, respectively (Fig. 1). Constancy of the delivery rate was verified at frequent intervals using a calibrated burette within the intravenous set-up, while $P_{\text {osmol }}$ were maintained at 270 mosmol $/ \mathrm{kg}$ during pregnancy and $275 \mathrm{mosmol} / \mathrm{kg}$ preconception and postpartum, by periodic ingestion of water. These tonicities should be sufficiently low to ensure suppression of endogenous AVP release, but to confirm this, plasma AVP-neurophysin levels were determined in three of the subjects on 15 test occasions. Finally, vasopressinase levels were monitored starting with the initial test, and then every 2-3 wk until the postpartum study.

\section{Analytical procedures}

Blood for osmolality and vasopressinase activity was collected in chilled heparinized tubes, small portions were immediately drawn for microhematocrit determination, and the remainder was centrifuged at $4^{\circ} \mathrm{C}$. Osmolality was determined by freezing point depression on an osmometer (model 3DII; Advanced Instruments, Inc., Needham Heights, MA) on freshly separated plasma, and the remaining sample was stored at $-20^{\circ} \mathrm{C}$ until used. Blood for AVP determination was collected in a $10-\mathrm{ml}$ syringe containing $0.1 \mathrm{ml}$ phenanthroline (1-20phenanthroline monohydrate; Sigma Chemical Co., St. Louis, MO) solution $(60 \mathrm{mg} / \mathrm{ml})$ and then rapidly added to chilled heparinized tubes, centrifuged in the cold, and extracted within $3 \mathrm{~h}$ of venipuncture. Validation of this technique, which immediately inactivates the high concentrations of cystine aminopeptidase (vasopressinase) present in the plasma of gravidas, is detailed elsewhere (2).

$R I A$ of $A V P$. Details of our extraction technique and assay procedures have been published (2). Briefly, plasma is extracted by a modification of the acetone method and 200- $\mu$ l samples are assayed by a nonequilibrium method. The tracer has a high specific activity $\left(>1,000 \mathrm{Ci} \times \mu \mathrm{g}^{-1}\right.$ ); highly purified AVP (potency, $400 \mathrm{U} / \mathrm{mg}$, lot 800207; Ferring Arzneimittal GbhG, Wittland, FRG) is used for iodination and standards, and our antiserum (10169) is quite specific and sensitive. Assay sensitivity is $0.1 \mathrm{pg} /$ assay tube, while its $50 \%$ displacement is $1.6 \mathrm{pg} /$ assay tube.

Vasopressinase activity. An index derived from the rapidity by which the enzyme degraded the ${ }^{125}$ I-AVP tracer was used to monitor vasopressinase activity during and after pregnancy $(5,6)$. Phenanthroline-free plasma $(1.0 \mathrm{ml})$ was incubated at $22^{\circ} \mathrm{C}$ with tracer $\left(2 \times 10^{5}\right.$ $\mathrm{cpm}$ ). 50- $\mu$ l aliquots were drawn before and 5, 10, 15, 30, and $60 \mathrm{~min}$ after incubation, and immediately diluted in $1 \mathrm{ml}$ chilled $4^{\circ} \mathrm{C}$ assay

data (4), as well as unpublished observations, which indicated that the delivery of substantially more hormone would be necessary to obtain measurable $P_{A V P}$ as gestation progressed. buffer containing phenanthroline $(60 \mathrm{mg} / \mathrm{ml})$, a step that inactivated the enzyme (2). Degradation of the iodinated tracer was measured by loss of binding to excess AVP antiserum and residual activity (at 60 $\mathrm{min}$ ) expressed as percentage of bound tracer from the aliquot obtained before incubation (usually $>95 \%$ ). Sensitivity of this index was compared with that of a standard photometric fluorometric assay that uses 5-benzyl-L-cystine-p-nitroanilide as a substrate (7).

$A V P$-neurophysin. Preparation of the antiserum, iodination of tracer, and RIA for AVP (nicotine-stimulated) neurophysin are described in detail elsewhere $(8,9)$. Briefly, $50 \mu l$ of plasma are assayed by a nonequilibrium technique, the minimal detectable level of neurophysin being $0.5 \mathrm{ng} / \mathrm{ml}$.

Calculations and statistical analysis. MCR was measured by a standard formula: infusion rate (calibrated during each study) multiplied by infusate AVP concentration (verified by RIA), divided by $P_{A V P}$ (mean of three separate determinations obtained after reaching equilibrium). To assess if a steady-state AVP level had been achieved during each of the three constant infusions of AVP per study, a test of piecewise linear trend was used $(10,11)$. To determine whether or not the MCR was significantly different at the three infusion rates, the values at each rate of infusion within each subject or each of the five test occasions were analyzed using an analysis of variance (ANOVA). From the significance of the $\mathrm{F}$ ratio from this analysis, comparison was performed using the $t$ test (11). Paired comparisons between test occasions were performed using $t$ test. For all analyses, values of $P \leq 0.05$ were considered significant. All data are given as mean \pm SD.

\section{Results}

Table I and Fig. 2 summarize results in all five subjects. Altering infusion rates produced similar $P_{A V P}$ levels at each stage of the serial study. $P_{A V P}$ during the final $30 \mathrm{~min}$ of all infusions were quite constant, demonstrating that steady-state levels had indeed been achieved by this time. This constancy is illustrated in Table II, which summarizes the mean variation and its SD for $P_{A V P}$ and $P_{\text {osmol }}$ at each infusion rate throughout the study. Not shown coefficients of variations were consistently below $10 \%$. These data again underscore the adequacy of steady-state values used to calculate the MCR in this investigation.

Of particular interest, the MCR in mid- and late pregnancy (3-4 liters/min) were fourfold those measured before conception, early in gestation, or postpartum (all $P<0.01$; Table I and Fig. 2). Small increases in hormonal disposal rates were noted during the first trimester (when osmotic secretory thresholds are decreasing or have just reached their lowest values, but the AVP response to osmotic stimuli $\left[\Delta \mathbf{P}_{\mathrm{AVP}}\right]$ $\Delta \mathbf{P}_{\text {osmol }}$ ] is similar to values in the nongravid state [3]), but these changes were not significant. Similarly, the MCR in late gestation were slightly higher than those in mid-pregnancy, but again these increments did not reach significance. In essence, the greatest changes took place between gestational weeks 6 and 8 and 22 and 24 .

Note also that the MCR at any stage was unaltered despite virtually tripling circulating hormone concentrations between the first and final infusion rates of each test. Table I and Fig. 2 depict relationships between $P_{A V P}$ and $U_{\text {osmol }}$ during each phase of the study. Similar $U_{\text {osmol }}$ were recorded when $\mathbf{P}_{\mathrm{AVP}}$ was comparable before, during, and after gestation.

Table I also contains AVP-neurophysin levels measured in three volunteers. Values before water loading were similar to those reported in the literature $(8,9)$ and became undetectable $(<0.5 \mathrm{ng} / \mathrm{ml})$ after hydration.

The MCR in the women with a single kidney and those carrying twins and triplets are summarized in Table III. These 


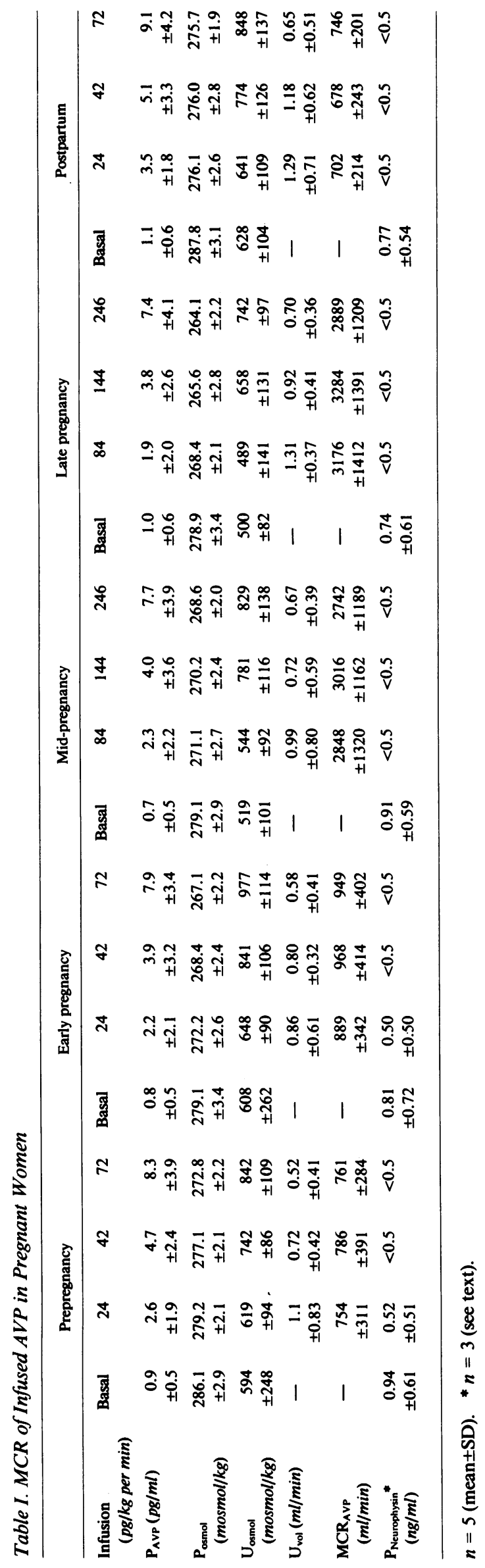

subjects, studied only during the third trimester and postpartum, were evaluated during an early phase of the investigation, before we appreciated the magnitude of the changes in MCR in late gestation, and when the experimental design at that time involved only a two-tier infusion. Not shown, only a single similar steady-state $P_{A V P}$ was achieved before and after pregnancy for each subject.

Fig. 3 compares vasopressinase activity derived by our isotope index and a standard substrate method. Activity was detected earlier in pregnancy using the tracer method (7-8 wk) and then the substrate technique (9-10 wk). Enzyme activity increased 40 -fold by mid- and 50 -fold by late pregnancy using either assay $(P<0.001)$, while vasopressinase remained detectable for a longer period after gestation using the tracer (5-6 wk) compared with the substrate (4 wk) assay. Not shown on the figure, enzyme levels in the women carrying twins and triplets were consistently at the upper 1 SD boundary, their final values near term being 270 and $281 \mathrm{mIU} / \mathrm{ml}$, respectively.

\section{Discussion}

We monitored clearances of exogenously infused AVP in five women starting before conception, continuing throughout pregnancy, and 8-10 wk postpartum. The MCR at mid- and late pregnancy was markedly increased compared with values in the first trimester as well as when the women were not pregnant. Hormonal disposal rates at any phase of the study were uninfluenced by the circulating levels of AVP and the increments observed during mid- and late gestation seemed to correlate with striking increases in vasopressinase activity present at these times. We also measured basal AVP in these subjects, noting that levels were similar throughout pregnancy as well as the nonpregnant state. Thus, hormonal production rates must also have increased by mid-gestation.

The observation that infused AVP is cleared more rapidly during gestation confirms and extends a recent report in which we suggested that the MCR of endogenously secreted hormone was increased in late pregnancy (12). This was based on observations during and after pregnancy in a protocol where $P_{A V P}$ had been increased secondarily to increments in $P_{\text {osmol }}$ induced by hypertonic saline infusion after which the subjects drank water, a maneuver that rapidly suppresses endogenous hormone release by an oropharyngeal-neuroendocrine reflex, even in the face of sustained hyperosmolality (12). Within minutes of drinking, AVP levels started to decrease and the hormonal $t_{1 / 2}$ in late gestation was half that in early pregnancy or postpartum. However, as noted in that report, peak AVP levels attained with hypertonic saline were too low (usually between 5 and $10 \mathrm{pg} / \mathrm{ml}$ ), and post-drinking blood samples with detectable $P_{\text {AVP }}$ too few, to accurately assess the $t_{1 / 2}$. Nevertheless, these previous observations add confidence to the conclusion that our present infusion clearance data reflect the MCR of endogenously secreted hormone. This is not a moot point for in pregnancy it is conceivable that the intravenous infusion of AVP might activate or increase plasma vasopressinase. In this respect circulating vasopressinase activity measured before, during, or after an infusion was similar in a given subject on any test occasion (Sheills, E. A., and J. M. Davison, unpublished observations).

The reason for the striking increments in MCR in late gestation is not apparent from our data and one can only 


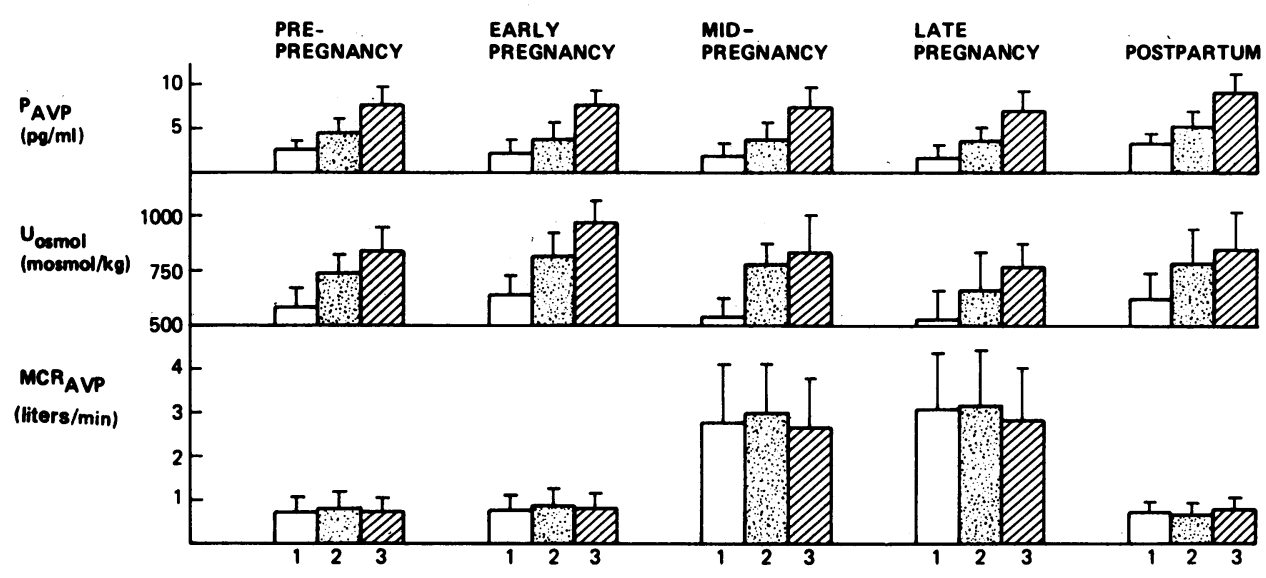

Figure 2. Summary of $\mathrm{P}_{\mathrm{AVP}}, \mathrm{U}_{\text {osmol }}$, and $\mathrm{MCR}_{\mathrm{AVP}},( \pm \mathrm{SD})$ measured serially in all five women starting before conception, then during gestational weeks 6-8, 22-24, and $36-38$, as well as $10-12$ wk postpartum. The three infusion rates are detailed in Fig. 1. speculate concerning causality. Renal and hepatic blood flow increase during gestation and the kidney and liver are organs where considerable AVP degradation takes place. Renal hemodynamics, however, increase quite early in pregnancy (at a time when the MCR is hardly altered), and the combined increments in flow to both organs (controversial for the liver and 30-50\% for the kidney) are far less than the increase in hormonal disposal recorded in mid- and late gestation (13). Also, the percent rise in MCR noted in the two gravidas with single kidneys was similar to that in the normal volunteers.

The placenta, the mass of which increases throughout gestation, may inactivate substantial quantities of AVP in situ. In preliminary studies we perfused ${ }^{125} \mathrm{I}-\mathrm{AVP}$ at rates comparable to in vivo conditions (14). The preparation perfused on the maternal side was capable of inactivating $\sim 1 \mathrm{ng} / \mathrm{min}$ of tracer, while perfusion of the fetal side was without effect.

Table II. Variation of $P_{A V P}$ and $P_{\text {osmol }}$ Measured at 15-min Intervals during Final 45 Min of Each Infusion during 225 Measurements of MCR Performed on Five Patients

\begin{tabular}{lrcc}
\hline & & \multicolumn{2}{c}{ Variation of } \\
\cline { 3 - 4 } & Infusion & $P_{\text {AVP }}$ & $P_{\text {oumol }}$ \\
\hline Prepregnancy & $p g / k g / m i n$ & $p g / m l$ & mosmol $/ \mathrm{kg}$ \\
& 24 & $0.52 \pm 0.29$ & $1.3 \pm 0.7$ \\
Early pregnancy & 42 & $0.44 \pm 0.28$ & $0.9 \pm 0.7$ \\
& 72 & $0.57 \pm 0.26$ & $0.9 \pm 0.9$ \\
Mid-pregnancy & 24 & $0.42 \pm 0.31$ & $1.2 \pm 0.9$ \\
& 42 & $0.63 \pm 0.34$ & $1.1 \pm 0.8$ \\
Late pregnancy & 72 & $0.50 \pm 0.29$ & $0.8 \pm 0.4$ \\
& 144 & $0.64 \pm 0.29$ & $0.9 \pm 0.9$ \\
& 246 & $0.61 \pm 0.26$ & $1.4 \pm 0.6$ \\
Postpartum & 84 & $0.43 \pm 0.27$ & $1.2 \pm 0.6$ \\
& 144 & $0.29 \pm 0.19$ & $0.9 \pm 0.9$ \\
& 246 & $0.41 \pm 0.20$ & $1.3 \pm 0.8$ \\
& 24 & $0.34 \pm 0.21$ & $1.1 \pm 0.8$ \\
& 42 & $0.56 \pm 0.34$ & $1.1 \pm 0.7$ \\
& 72 & $0.61 \pm 0.32$ & $1.1 \pm 0.7$ \\
& & $0.53 \pm 0.34$ & $1.5 \pm 0.6$ \\
\hline
\end{tabular}

Mean $\pm S D ; n=5$ patients.
Thus, the placenta too may account for the increased MCR observed on these studies. Of interest, also, is that estimated trophoblastic mass increases 1,000 -fold between gestational weeks 6 and 24, plateauing thereafter (15). Uteroplacental blood flow follows a similar pattern of change, and at term has been estimated to be about $500 \mathrm{ml} / \mathrm{min}$ blood flow (16). In these respects the MCR of AVP was almost maximal by 22-24 wk, increasing slightly but not significantly near term.

The placenta is also the source of circulating vasopressinase, an enzyme capable of inactivating large quantities of AVP in vitro. Whether or not this enzyme is active in vivo, however, is unclear, but it is of interest that alterations in the hormonal MCR correlated best with increments in plasma vasopressinase in the present study. Of further interest, pregnant sheep, whose placentae produce no detectable vasopressinase, do not have an increased MCR of AVP during their gestation (17). Currently we are measuring the MCR of 1-desamino-[8-D-arginine]vasopressin (DDAVP), an AVP analogue resistant to enzymatic inactivation by cystine-aminopeptidase (18). If vasopressinase does play a role in the increased MCR of AVP during mid- and late gestation, any increments in the disposal rate of infused DDAVP ought to be considerably less than those observed for the native hormone.

Oxytocin, which differs from AVP by just two amino acids, is also inactivated in vitro by cystine-aminopeptidase, and thus might be expected to be metabolized in a manner similar to vasopressin in pregnant women. Surprisingly, however, Amico et al. observed no differences in the MCR of infused oxytocin into term pregnant subjects compared with nonpregnant vol-

Table III. MCR of AVP in Third Trimester and Postpartum in One Woman with Twins, Another with Triplets, and Two Subjects with a Single Kidney

\begin{tabular}{lcccc}
\hline & \multicolumn{2}{c}{ Third trimester } & \multicolumn{2}{c}{ Postpartum } \\
\hline Infusion $(\mathrm{pg} / \mathrm{kg} \mathrm{per}$ min $)$ & 84 & 144 & 42 & 72 \\
MCR & & & & \\
$\quad$ Twins $(\mathrm{ml} / \mathrm{min})$ & 3,417 & 2,994 & 981 & 818 \\
Triplets $(\mathrm{ml} / \mathrm{min})$ & 2,627 & 2,588 & 812 & 729 \\
One kidney $(\mathrm{ml} / \mathrm{min})$ & 1,895 & 2,806 & 339 & 550 \\
One kidney $(\mathrm{ml} / \mathrm{min})$ & 2,318 & 2,103 & 553 & 621 \\
& & & & \\
\end{tabular}




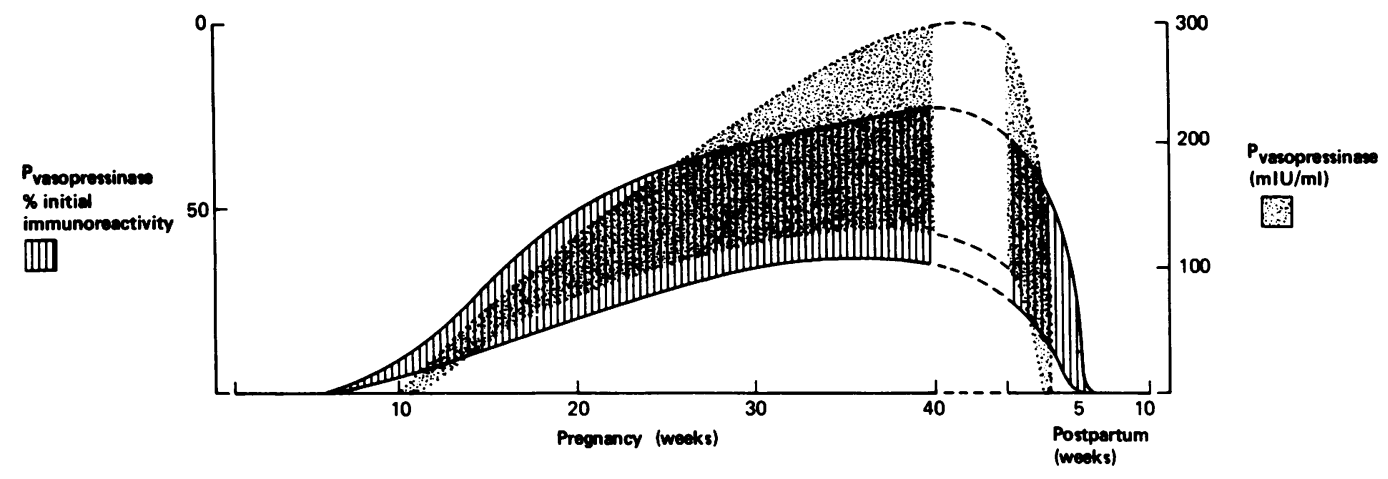

Figure 3. Plasma vasopressinase activity measured serially in the five women who underwent the metabolic clearance studies. Measurements of $P_{\text {vasopressinase }}$ started before conception and were repeated at 2-3-wk intervals until postpartum weeks 10-12. Two indices were used, one derived from the rapidity by which the enzyme de-

graded ${ }^{125}$ I-AVP tracer (vertical lines) and the other by photometry using 5-benzyl-L-cystine-p-nitroanilide as substrate (speckled area). Solid and dashed lines enclosing the vertical lines and speckled area represent \pm 1 SD.

unteers (19). However, there is evidence that oxytocin may be more resistant to enzymatic degradation in vivo, especially in the central nervous system (20). Also, and in contrast with observations reported by Amico et al. (19), we have preliminary data that suggest that the MCR of infused oxytocin is increased in a manner similar to that of AVP at term (21).

The increased MCR of AVP in pregnancy may explain certain other changes in osmoregulation during gestation. As noted previously, the rise in circulating hormone provoked by increasing body tonicity $\left(\Delta \mathbf{P}_{\mathrm{AVP}} / \Delta \mathrm{P}_{\text {osmol }}\right)$ decreases in the third trimester. Initially we considered that this might reflect a reduced secretory response to osmotic stimuli, as occurs in certain hypervolemic states such as primary aldosteronism (22), for indeed extracellular volume increases markedly in pregnancy (23). However, the osmotic sensitivity to thirst ( $\Delta$ thirst intensity $/ \Delta \mathrm{P}_{\text {osmol }}$; see reference 3 ) would also be expected to be decreased in such circumstances (24) and it was not (3). Another possibility considered was that an increase in hormonal disposal rate would explain reductions in the ratio $\Delta \mathrm{P}_{\mathrm{AVP}} / \Delta \mathrm{P}_{\text {osmol }}$ with little influence on the relationship between thirst intensity and $P_{\text {osmol }}$. This led to the current study and data supporting the latter hypothesis.

Several problems in water handling known to occur in pregnancy may also relate to our observations. For example, some women with central DI may require more AVP during gestation. There is a syndrome labeled transient DI of pregnancy that usually presents during the second half of gestation and remits postpartum (25). Some of the women with this complication may have subclinical lesions of central DI brought to the fore by the increased hormonal MCR of pregnancy (25-27). Still other patients have been described with transient vasopressin-resistant DI and high circulating levels of vasopressinase, and one of them described by Dürr et al. (5) responded to DDAVP after large doses of AVP had failed to effect $\mathrm{U}_{\text {osmol }}$.

Performance of a serial study also allowed us to evaluate the influence of pregnancy on renal effects of AVP. Some have suggested resistance to the hydroosmotic effects of AVP upon the kidney during gestation, both in humans and in two animal species (28-31). Several reasons, including increments during pregnancy in $\mathrm{PGE}_{2}$ excretion, a hormone that opposes the effects of AVP at the tubular level, have been offered to explain this resistance. Review of the literature, however, reveals that such claims have been based solely on the influence of exogenously administered hormone on $U_{\text {osmol }}$, without not- ing if such maneuvers achieve similar $\mathbf{P}_{\mathrm{AVP}}$ levels during the pregnant and nonpregnant states. For example, administration of similar quantities of AVP during the nongravid and pregnant states would be expected to produce lower $P_{A V P}$ values in the latter if either the MCR or volume of distribution were increased in pregnant and control subjects or animals. Our experiments permitted comparison of $U_{\text {osmol }}$ at similar AVP levels, measured during steady-state conditions. Similar levels of $P_{A V P}$ produced approximately the same $U_{\text {osmol }}$ in early, mid-, and late gestation as well as in the nonpregnant state (Table I and Fig. 2).

Finally, our observations in postpartum subjects are consistent with the MCR for AVP measured in nonpregnant populations and reported by Robertson et al. (32), Beardwell et al. (33), and Moses and Steciak (34), who used constant-infusion techniques, and Engel et al. (35), who performed a single-injection protocol. Moses and Steciak, however, observed increments in the MCR as $P_{A v P}$ increased, but we did not. This discrepancy may be explained by the fact that we measured $\mathbf{P}_{\mathrm{AVP}}$ at three levels within the physiological range, while even the lowest concentrations observed by Moses and Steciak (34) were supraphysiological.

In conclusion, these data demonstrate that the MCR of AVP similar to nonpregnant values during gestational weeks 7-8 measures fourfold by weeks $22-24$ and remains at these elevated levels through term. These rises seem to parallel the periods of rapid increase in both trophoblastic mass and circulating vasopressinase. The increase in hormonal disposal rates may explain the appearance of certain polyuric syndromes in late gestation.

\section{Acknowledgments}

We thank Ms. P. Papadatos and Ms. I. White for excellent secretarial assistance.

This work was supported by the Medical Research Council, Great Britain, National Institutes of Health grants HD-5572, 24498, and RR-55, and a Clinical Investigator Award (HL-01145) to William M. Barron.

\section{References}

1. Davison, J. M., M. B. Vallotton, and M. D. Lindheimer. 1981. Plasma osmolality and urinary concentration and dilution during and after pregnancy: evidence that lateral recumbency inhibits maximal urinary concentrating ability. Br. J. Obstet. Gynaecol. 88:472-479. 
2. Davison, J. M., E. A. Gilmore, J. Dürr, G. L. Robertson, and M. D. Lindheimer. 1984. Altered osmotic thresholds for vasopressin secretion and thirst in pregnancy. Am. J. Physiol. 246:F105-F109.

3. Davison, J. M., E. A. Shiells, P. R. Philips, and M. D. Lindheimer. 1988. Serial evaluation of vasopressin release and thirst in human pregnancy. Role of human chorionic gonadotrophin in the osmoregulatory changes of gestation. J. Clin. Invest. 81:798-806.

4. Davison, J. M., W. M. Barron, and M. D. Lindheimer. 1987. Metabolic clearance rates of vasopressin increase markedly in late gestation: a possible cause of polyuria in pregnant women. Trans. Assoc. Am. Phys. 100:91-98.

5. Dürr, J. A., J. G. Hoggard, J. M. Hunt, and R. W. Schrier. 1987. Diabetes insipidus in pregnancy associated with abnormally high circulating vasopressinase activity. $N$. Engl. J. Med. 316:1070-1074.

6. Dürr, J. A., R. W. Schrier, and M. D. Lindheimer. 1985. A new method for measuring vasopressinase activity in plasma. Clin. Res. 33:26A. (Abstr.)

7. Small, C. W., and W. B. Watkins. 1974. S-benzyl-L-cystine-pnitroanilide: a new substrate for the determination of oxytocinase with improved specificity. Biochem. Med. 9:103-112.

8. Robinson, A. G., E. A. Zimmerman, E. G. Engeleman, and A. G. Frantz. 1971. Radioimmunoassay of bovine neurophysin: specificity of neurophysin I and neurophysin II. Metab. Clin. Exp. 20:1138-1147.

9. Robinson, A. G. 1975. Isolation, assay and secretion of individual human neurophysin. J. Clin. Invest. 55:360-367.

10. Johnson, R. A., and D. W. Wichern. 1982. Applied Multivariate Statistical Analysis. Prentice Hall, Englewood Cliffs, NJ. 107 pp.

11. Armitage, P. 1980. Statistical Methods in Medical Research. Blackwell Scientific Publications Ltd, Oxford, UK. 504 pp.

12. Davison, J. M., E. A. Shiells, P. R. Philips, and M. D. Lindheimer. 1988. Suppression of AVP release by drinking despite hypertonicity during and after gestation Am. J. Physiol. 254:F588-F592.

13. Davison, J. M. 1987. Kidney function in pregnant women. Am. J. Kidney Dis. 9:248-252.

14. Landon, M. J., M. D. Lindheimer, and J. M. Davison. 1987. Degradation of radiolabelled arginine vasopressin ( ${ }^{125} \mathrm{I}-\mathrm{AVP}$ ) by human placentae perfused in vitro. Soc. Gynecol. Invest. Annu. Meet. Atlanta. 137.

15. Braunstein, G. D., J. L. Rasor, E. Engrall, and M. E. Wade. 1980. Interrelationships of human chorionic gonadotropin, human placental lactogen and pregnancy-specific B1-glycoprotein throughout normal human gestation. Am. J. Obstet. Gynecol. 138:1205-1213.

16. Faber, J. J., and K. L. Thornburg. 1983. Placental Physiology. Raven Press, New York. 33-54.

17. Bell, R. J., B. M. Laurence, P. J. Meehan, M. Congin, B. A. Scoggins, and E. M. Wintour. 1986. Regulation and function of arginine vasopressin in pregnant sheep. Am. J. Physiol. 250:F777-F780.

18. Edwards, C. R. W., M. J. Kitau, T. Chard, and G. M. Besser. 1973. Vasopressin analogue DDAVP in diabetes insipidus: clinical and laboratory studies. Br. Med. J. iii:375-378.

19. Amico, J. A., J. Seitchick, and A. G. Robinson. 1987. Clearance studies of oxytocin in humans using radioimmunoassay measure- ments of the hormone in plasma and urine. J. Clin. Endocrinol. Metab. 64:340-345.

20. Burbach, J. P. H., Z. Wang, and M. Ittersum. 1982. Difference in susceptibility of arginine-vasopressin and oxytocin to aminopeptidase activity of brain synaptic membranes. Biochem. Biophys. Res. Commun. 108:1165-1168.

21. Thornton, S., J. M. Davison, and P. H. Baylis. 1988. The metabolic clearance rate of oxytocin is increased during gestation. $J$. Endocrinol. 122(Suppl):159.

22. Ganguly, A., and G. L. Robertson. 1980. Elevated threshold for vasopressin release in primary hyperaldosteronism. Clin. Res. 28:330A. (Abstr.)

23. Gallery, E. A. M. 1984. Volume homeostasis in normal and hypertensive human pregnancy. Semin. Nephrol. 4:221-231.

24. Robertson, G. L. 1984. Abnormalities of thirst regulation. Kidney Int. 25:460-469.

25. Durr, J. A. 1987. Diabetes insipidus in pregnancy. Am. J. Kidney Dis. 9:276-283.

26. Baylis, P. H., C. Thompson, J. Burd, W. M. G. Tunbridge, and C. A. Snodgrass. 1986. Recurrent pregnancy-induced polyuria and thirst due to hypothalamic diabetes insipidus: an investigation into possible mechanisms responsible for polyuria. Clin. Endocrinol. 24:459-460.

27. Hughs, J. M., W. M. Barron, and M. C. Vance. Recurrent diabetes insipidus associated with pregnancy and pathophysiology and therapy. Obstet. Gynecol. In press.

28. Kleeman, C. R., and H. Vorherr. 1974. Water metabolism and neurohypophyseal hormones. In Duncan's Disease of Metabolism. P. K. Bondy and L. E. Rosenberg, editors. W. B. Saunders Company, Philadelphia. 1479.

29. Olsson, K., S. Benlamih, K. Dahlborn, and F. Fyrquisit. 1982. Effect of water deprivation and hyperhydration in pregnant and lactating goats. Acta Physiol. Scand. 115:361-367.

30. Olsson, K. 1986. Pregnancy: a challenge to water balance. News Physiol. Sci. 1:131-134.

31. Barron, W. M., J. Dürr, B. A. Stamoutsos, and M. D. Lindheimer. 1985. Osmoregulation and vasopressin secretion during pregnancy in Brattleboro rats. Am. J. Physiol. 248:R29-R37.

32. Robertson, G. L., E. A. Mahr, S. Athar, and T. Swika. 1973. The development and clinical application of a new radioimmunoassay for arginine vasopressin in human plasma. J. Clin. Invest. 52:23402352.

33. Beardwell, C. G., G. Geelen, H. M. Palmer, D. Roberts, and L. Salamonson. 1973. Radioimmunoassay of plasma vasopressin in physiological and pathological states in man. J. Endocrinol. 67:189202.

34. Moses, A. M., and E. Steciak. 1986. Urinary and metabolic clearance of arginine vasopressin in normal subjects. Am. J. Physiol. 251:R365-R370.

35. Engel, R., J. Rowe, K. Minaker, and G. L. Robertson. 1984. Effect of exogenous vasopressin on vasopressin release. Am. J. Physiol. 246:E202-E207. 